\title{
On the influence of basic thermodynamics on thermal cracking resistance of asphalt mixtures in cooling tests
}

\author{
Daniel Steiner ${ }^{a}$, Bernhard Hofko a* \\ a Institute of Transportation, TU Wien, Austria
}

Received: 23 February 2018 / Accepted: 05 July 2018 / Published online: 12 July 2018

(c) The Author(s) 2018. This article is published with open access and licensed under a Creative Commons Attribution 4.0 International License.

\begin{abstract}
The cooling test or Thermal Stress Restrained Specimen Test (TSRST) simulates fully restrained pavements, as they occur in field for laboratory assessment of the thermal cracking resistance of asphalt mixtures. In the TSRST, cryogenic stress builds up due to cooling and prevented shrinkage until the tensile strength of the specimen is exceeded and the specimen fails by cracking. By carrying out TSRST various viscoelastic parameters, e.g. relaxation, evolution of tensile stresses, and tensile strength can be analyzed. Thus, a comprehensive view on the low temperature performance is possible. Standard TSRST is controlled by setting the cooling rate of the air within the chamber at a fixed value, e.g. $-10^{\circ} \mathrm{C} / \mathrm{h}$. In thermodynamics, the actual cooling rate of objects is not only influenced by the cooling but also by external conditions like humidity, air velocity, radiation condition, etc. A current study investigates the impact of additional cooling parameters rather than just the air cooling rate. Two test machines of the same manufacturer that differ in the year of production and the setup of the climate chamber are compared. An initial wide scatter of test results from the two devices could be explained by taking thermodynamics into account and the reproducibility could be significantly enhanced.
\end{abstract}

Keywords: Asphalt mixtures; Cooling test; TSRST; Thermal cracking

\section{Introduction}

Asphalt mixtures are the dominant construction material for today's road pavements, e.g. about $90 \%$ of the paved US road network is made of asphalt pavements [1], and by far more than 90\% of the European road network. [2] Asphalt mixtures are a composite of asphalt binder and mineral aggregates with a predefined mix design. A fundamental characteristic of asphalt is its viscoelastic material behavior. Due to its viscoelasticity, pavements can be constructed without transverse joints since thermally induced stresses upon temperature changes can be relaxed by the binder. However, the material behavior is highly temperature dependent; at low temperatures it shifts towards an elastic, brittle state [3]. Thus, when the temperature falls below a certain value, the stress relaxation capability of the binder is not sufficient and once the tensile strength is reached, the asphalt pavement will fail by thermal cracking. These cracks allow for water to penetrate the pavement, leading to further frost-thaw damage and eventually complete disintegration of a pavement structure. The stress relaxation capability depends on multiple factors including binder grade, binder modification, aging susceptibility of the binder, mix design, etc. To ensure durable pavement structures, it is important to assess the thermal cracking resistance at the stage of mix design. For this reason, various test methods have been developed in the last decades. One of the commonly employed methods is the thermal stress restrained specimen test (TSRST) or cooling test. This method has been introduced and improved from the 1960s on by Monismith et al., Fabb and Arand [4-6]. It has been in the focus of researchers working on the low temperature behavior ever since. Impact of binder modification on thermal cracking has been studied [7-10] and preliminary correlation between binder chemistry and thermal cracking resistance has been set up [11]. Also, the thermal cracking behavior has been described by various models [12-15]. Recently, studies on the impact of warm mix asphalt (WMA) [16], rubberized binders [17] and the correlation to field performance [18] have been carried out.

The TSRST has been standardized by EN 12697-46 [19] to make it available to public contracting for road works. In the TSRST, an asphalt mix specimen is mounted within a test device in a thermal chamber. The length of the specimen is kept constant while the thermal chamber cools down the specimen with a constant rate until the specimen fails. The 
cryogenic stress and failure temperature are recorded. The standard clearly defines the accuracy and resolution of the loading device, the load cell and the deformation measurement system, as well as the thermal chamber. These definitions are set to ensure repeatable and reproducible results from TSRST. A repeatability of $\pm 1^{\circ} \mathrm{C}$ for the failure temperature and $\pm 0.25 \mathrm{MPa}$ for the failure stress are given. No information on the reproducibility is stated so far.

The paper is structured in 5 chapters. Chapter 1 gives a brief introduction into the topic. In chapter 2, the problem statement and objectives are presented. Materials and Test Methods are documented in chapter 3 and 4. Finally, all relevant results of the study are given in chapter 5 . Furthermore all findings are interpreted and finally a summary and outlook of further needed investigations are given.

\section{Problem Statement and Objectives}

Two different devices from the same manufacturer for TSRST are run at the authors' laboratory. One device was manufactured in 2003 and the other device in 2013. Both machines are built with the same concept. A central positioned specimen is mechanically loaded with two rods on top and bottom of the specimen. The Specimen is surrounded and conditioned with an environmental chamber. Both loading roads are routed through the wall of the chamber and are mounted on an unconditioned load frame. Beside the different year of manufacture, the devices consists of environmental chambers with different sizes. The older device will be labelled "2003" throughout the paper, while the newer one will be labelled "2013". Both devices comply with all accuracy and resolution settings given by US and European Standard. However, a comprehensive test program that was carried out to ensure that both devices deliver comparable results revealed that there is a systematic deviation in results obtained from both devices when specimens from the same hot mix asphalt (HMA) slab were tested. Figure 1 shows example results of this study. The left diagram contains the cryogenic stress vs. specimen temperature for each tested specimen and the right diagram shows the final results, the mean value of failure stress and temperature of three tested specimens. While the results in terms of failure stress are close (4.6 vs. $4.9 \mathrm{MPa}$ ) and even within the repeatability range, the failure temperature deviates by more than $3^{\circ} \mathrm{C}$. The trend that the 2013 device always produced worse results, i.e. higher failure temperatures was observed for more than 10 different asphalt mixtures.

The length control of a TSRST plays a vital role in controlling the test over the time. Small deviations can lead to changes in the restrained specimen condition and subsequently the stress evaluation.

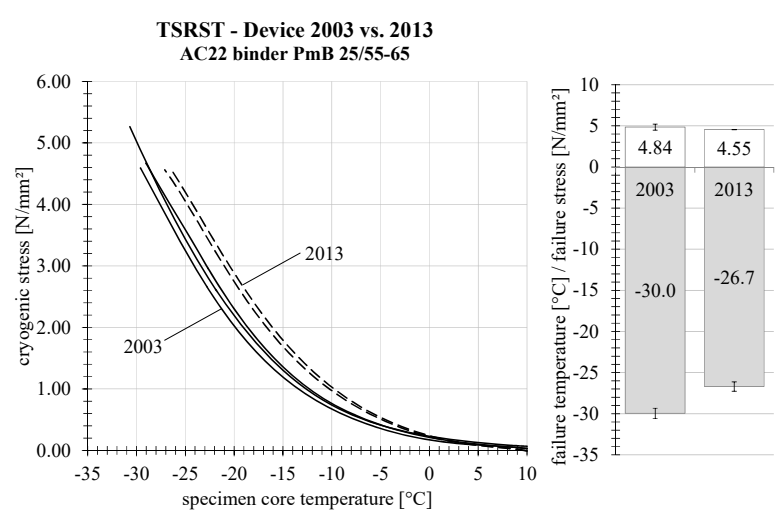

Figure 1. Example of TSRST results from 2003 (left bar) and 2013 (right bar) device.

Hence, one obvious hypothesis for the deviation in results is that one of the devices does not keep the length of the specimen constant However, a detailed analysis of the recorded data from the LVDTs (Linear Variable Differential Transformers) that are used for deformation control reveals that both devices show high precision. Figure 2 presents example results from one test: LVDT readings vs. specimen core temperature. Apparently, both devices show a certain noise but the change in length is below $5 \mu \mathrm{m} / \mathrm{m}$ for both devices. Thus, a significant impact of the deformation control can be omitted.

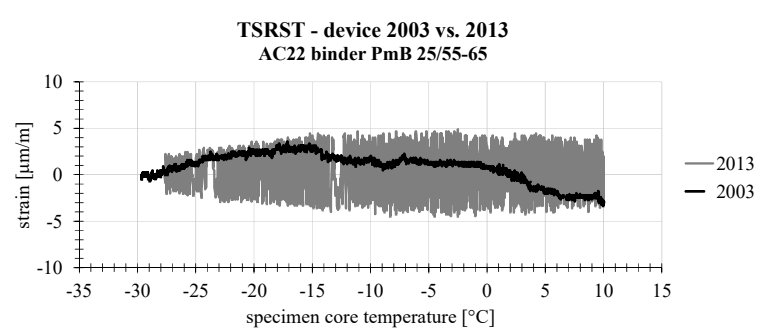

Figure 2. Strain vs. specimen temperature in TSRST.

The evolution of cryogenic stresses in TSRST is affected by the following factors: the accuracy of the length control and air and specimen temperature. Thus, the second hypothesis was that there is a difference in the air temperature control in the two devices. Figure 3 shows temperature recordings from a TSRST for the 2003 and 2013 device. The left diagram presents the evolution of temperature over time. While the black curve gives the ideal temperature profile with $-10^{\circ} \mathrm{C} / \mathrm{h}$, the green lines show the actual air and specimen core temperature for the 2013 device, while the red/orange lines show the same data for the 2003 device. The right diagram shows the temperature rate within the linear part between hours 2 and 4 . In both devices, the air temperature follows a $-10^{\circ} \mathrm{C} / \mathrm{h}$ rate with only a small deviation, the 2013 device being $3 \%$ too fast, the 2003 device about $1 \%$ too slow. 


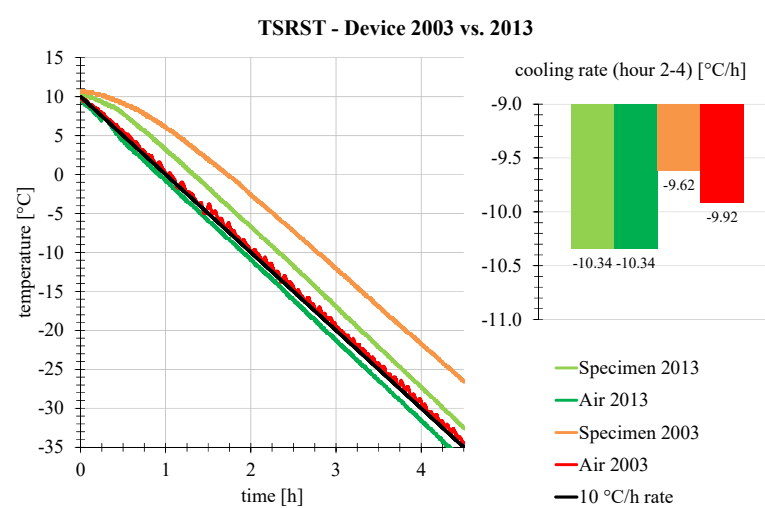

Figure 3. Air and specimen core temperature in a TSRST for 2003 and 2013 device.

However, it is interesting to observe that in the 2013 device, the specimen core cools down with the same rate as the air temperature, whereas in the 2003 device, the specimen core cools down significantly slower. This means that the temperature lag between air and specimen core temperature is clearly larger for the 2003 device than for the 2013 device. After 3 hours, the specimen core is $4.2^{\circ} \mathrm{C}$ warmer than the air for the 2013 device but $7.2^{\circ} \mathrm{C}$ warmer for the 2003 device. This difference can explain why the 2003 device produces better results since the specimen cools down more slowly and therefore, cryogenic stresses are built up at a slower pace. This prolongs the period of stress relaxation in the 2003 device and leads to a later failure, i.e. lower failure temperatures.

However, since the air temperature rates are comparable in both devices, the larger deviation between air and specimen core temperature in the 2003 device cannot be explained by a significant difference in air cooling temperature. Investigating reasons for this temperature deviation is subject of this paper. Possible solutions for this problem will be presented and recommendations are given on how to improve US and European testing standards to ensure that the described problems can be prevented in the future. This can improve the reproducibility of results obtained from TSRST in different devices.

\section{Materials}

To investigate the issue about deviating TSRST results in the 2003 and 2013 device as a consequence of difference in specimen core cooling rate more thoroughly, a test program has been carried out for a number of different specimens with different mix designs and specimen dimensions.

Table 1 shows all considered asphalt mix types and the regarding specimen dimensions. As it can be seen, two asphalt concrete (AC) 16 (mm maximum nominal aggregate size) samples have been analysed. ACs show a dense grading curve and low air void content. Specimen cross sections of $5 \times 5 \mathrm{~cm}$ and $6 \times 6 \mathrm{~cm}$ were included in the test program to investigate the impact of cross section on temperature deviation. In addition, an AC 22, as well as a mastic asphalt (MA) 8 were taken into account. Mastic asphalts show a dense grading curve as well but a much higher binder content (around $9 \mathrm{M} \%$ ) compared to other mix types. Thus, no air voids are present in MAs. This could have an effect on the temperature conductivity of the material. Finally, a stone mastic asphalt (SMA) 11 was included into the study. SMAs show a gap aggregate grading. The filler and coarse aggregate fraction dominates this asphalt mix type, which could also affect the temperature conductivity of the material.

Table 1. Overview of analysed asphalt mixes and specimen dimensions

\begin{tabular}{|c|c|}
\hline Asphalt Mix Type & Specimen Dimensions $\left[\mathrm{cm}^{3}\right]$ \\
\hline AC 16 surface & $5 \times 5 \times 9.7$ \\
\hline AC 16 surface & $6 \times 6 \times 9.7$ \\
\hline AC 22 binder & $6 \times 6 \times 9.7$ \\
\hline MA 8 & $5 \times 5 \times 9.7$ \\
\hline SMA 11 & $5 \times 5 \times 9.7$ \\
\hline
\end{tabular}

\section{Test Methods and Test program}

\subsection{Test Methods}

Both devices, 2003 and 2013, work in a similar way. The load frame is located inside a thermal chamber. The specimen is glued to two adapter plates at both ends before it is mounted into the device by bolting the adapter plates to the load frame. The applied load is constantly monitored by a load cell outside of the thermal chamber. Changes in length are driven by an electromechanic step motor. To monitor and control the specimen length, two additional adapters are fixed to the upper and lower adapter plates. These additional adapters hold four Invar ${ }^{\circledR}$ steel rods. Invar has a very low thermal expansion coefficient. The rods exit the thermal chamber through its bottom and are connected to LVDTs outside of the thermal chamber. These four LVDTs located at $90^{\circ}$ around the specimen are responsible for length control. The complex mechanism of transferring the specimen displacements via Invar steel rods outside of the thermal chamber is necessary, since LVDT readings are affected by temperature changes. By placing the LVDTs outside the thermal chamber, this effect can be prevented. The thermal expansion of the Invar steel roads are taken into account and are compensated by the test procedure. The length control of the specimen is carried out by taking the mean value of the four LVDTs and keeping the LVDT readings constant throughout the test. Figure 6 and Figure 7 show details of both test devices. The adapters, adapter plates, the glued specimen and the temperature dummy can be seen. The temperature chambers are different in terms of internal dimensions and power of the cooling unit: width $\times$ height $\times$ depth $\left[\mathrm{cm}^{3}\right]$ 2003: $40 \times 60 \times 36 \mid$ 2013: $60 \times 90 \times 60.2003$ : $1.5 \mathrm{~kW}$ | 2013: $3.5 \mathrm{~kW}$.

To record the core temperature of the specimen a dummy specimen is prepared for each mixture that is tested in the laboratory. This enables to take into account the structure of the compacted mixture. Thermal conductivity is not only influenced by the mix design, but also by the compaction quality resulting in the air void content. The dummy 
specimen is taken from the same HMA slab as the test specimens to make sure that the thermal behavior is the same for dummy and test specimen. Mixes are prepared in a laboratory reverse-rotation compulsory mixer, according to EN 12697-35. HMA Slabs $\left(50 \times 26 \times 5 / 6 \mathrm{~cm}^{3}\right)$ are compacted in a roller compactor according to EN 12697-33. From the slabs, seven to eight specimens are cut $(5 \times 5 \times 22.5$ / $\left.6 \times 6 \times 22.5 \mathrm{~cm}^{3}\right)$. One of the specimens is shortened to prepare the assigned thermal dummy specimen to each set of test specimens for the TSRST.
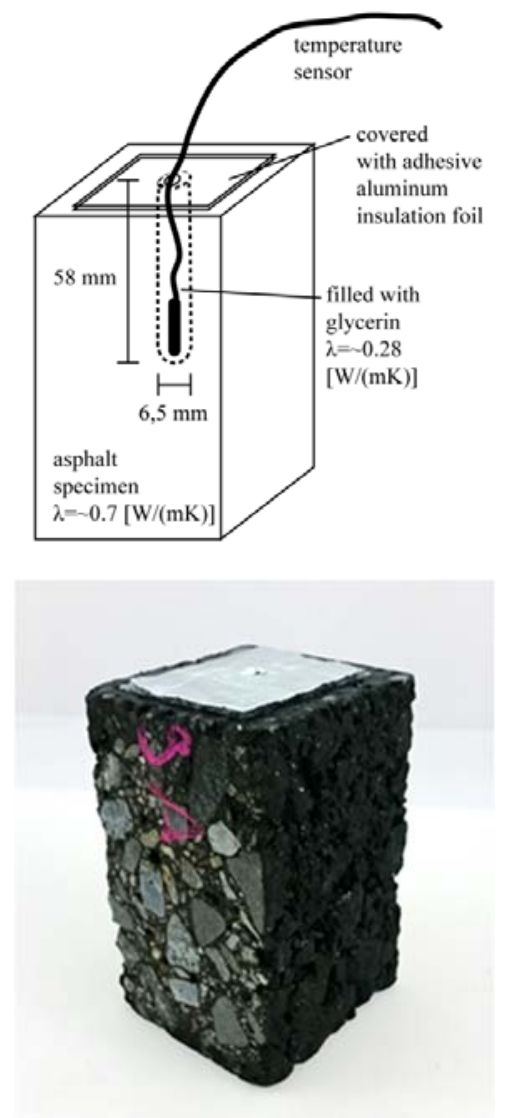

Figure 4. Schematic view and photo of a dummy specimen.

An example of a dummy is presented in Figure 4. The dummy specimen is cut in half and a hole is drilled in the centre of one end plane. The hole is covered with an adhesive aluminum insulation foil to limit heat loss to the surface. The hole is filled with glycerine and a temperature probe is inserted into the hole to record the core temperature. The asphalt mixture $(\lambda=0.7 \mathrm{~W} /(\mathrm{mK}))$ conducts the heat better than glycerin $(\lambda=0.28 \mathrm{~W} /(\mathrm{mK}))$. The glycerin prevents thermal bridges in the drilling direction of the hole. [20]. The dummy is placed in the thermal chamber close to the actual test specimen at the same height to make sure that both, the dummy and test specimen are subject to the same temperature profile in the chamber.

For the study presented in this paper, one dummy specimen for each considered asphalt mix was produced. The dummy specimen was placed into the thermal chamber at the position, where the glued specimen would be mounted at actual TSRST test. The thermal program that is used for TSRST was run: It starts at a temperature of $+10^{\circ} \mathrm{C}$ and holds this temperature for $60 \mathrm{~min}$ to make sure that the complete specimen is in thermal equilibrium. After $60 \mathrm{~min}$, the thermal chamber cools down with an air temperature rate of $10^{\circ} \mathrm{C} / \mathrm{h}$ until and air temperature of $-40^{\circ} \mathrm{C}$ is reached. Air and specimen core temperature are recorded every 4 seconds. In addition, air flow velocity was measured for the standard setup with a compact vane anemometer.

\subsection{Test Program}

The procedure described above was run for each asphalt mix dummy specimen and in thermal chambers of both, the 2003 and 2013 device. For one dummy specimen, the air velocity was increased by additional fans in 3 steps in the 2003 device. In every test, the air temperature and specimen core temperature were recorded. The employed data logger can read 4 PT100 sensors simultaneously. One sensor measured the specimen core temperature, while the 3 additional sensors were spread over the chamber (bottom, center next to the specimen, top). For this paper, only the air temperature from the centered sensor was analyzed.

\section{Results and Interpretation}

As already shown in the problem statement, both devices exhibit a precise control of constant specimen length throughout the specimen but the temperature lag between air and specimen core is different in the 2003 and 2013 device. This is a plausible explanation for the deviation in failure temperature.

To analyze this effect in more details, temperature profiles for the thermal program of the TSRST were recorded for five different asphalt mixtures. The results are shown in Figure 5. The left diagram shows the temperature lag between air and specimen core temperature for each mix in both devices vs. the simulated TSRST temperature. The simulated TSRST temperature is the cooling rate that perfectly follows the standard specification $\left(10{ }^{\circ} \mathrm{C} / \mathrm{h}\right)$ calculated from the set starting time. The right diagram shows the maximum temperature lag for each mix and both devices. Comparing the different asphalt mix types, the SMA shows the smallest temperature lag $\left(3.6^{\circ} \mathrm{C}\right.$ max $2013,8.4^{\circ} \mathrm{C}$ max 2003). This can be explained with the higher content of coarse aggregates and therefore a better temperature conductivity of the material. MA 8 with high binder content and AC $16(5 \times 5$ $\mathrm{cm}^{2}$ ) both show very similar temperature lags. Obviously, the higher air void content of an AC does not reflect on the temperature conductivity. A clear difference can be found between specimen $5 \times 5 \mathrm{~cm}^{2}$ and $6 \times 6 \mathrm{~cm}^{2}$ cross section. While the maximum lag is $8.4^{\circ} \mathrm{C}(2003)$ and $3.5^{\circ} \mathrm{C}$ (2013) for the AC $165 \times 5 \mathrm{~cm}^{2}$ specimen, it increases by $0.8^{\circ} \mathrm{C}$ to $9.2^{\circ} \mathrm{C}$ (2003) and by $0.9^{\circ} \mathrm{C}$ to $4.4^{\circ} \mathrm{C}$ (2013).

For every asphalt mix type, the temperature lag is significantly higher for the 2003 device compared to the 2013 device. On average, the 2003 device shows $4.7^{\circ} \mathrm{C}$ higher max temperature lag. 


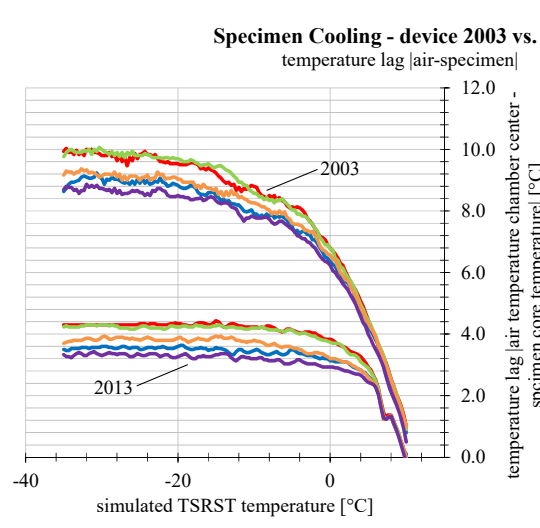

Figure 5. Temperature lag between specimen core and air temperature for both devices.

As mentioned in the introduction, the difference in cooling rate and air temperature in both devices is negligible. Thus, the differences in temperature lag between air and specimen core temperature between the two devices cannot be explained by a difference in air temperature profile or cooling rate.

The essential evidence for explaining the effect shown above was a measurement of air flow velocity in both devices for the standard setup. The vane anemometer (vane diameter $2.5 \mathrm{~cm}$ ) can measure the air velocity continuously. The measurements showed that it is extremely difficult to define the air velocity of a cuboid chamber. Due to the surrounding walls, the air stream is reflected multiple times creating turbulent flows, which change with measurement position. Nevertheless the data show different air velocities on specimen height in vertical directions. The 2003 device with a smaller chamber has a lower air velocity $(0.5 \mathrm{~m} / \mathrm{s})$ than the 2013 device with the larger chamber $(1.4 \mathrm{~m} / \mathrm{s})$.

The effect of lower air flow velocities in the 2003 device is increased by a different design of the adapters holding the Invar steel rods. Figure 6 shows two details of the 2003 and 2013 test device. The top picture presents the adapter in the 2003 device, the bottom picture in the 2013 device. While the 2003 device has a solid plate to hold the rods, the 2013 device is a much lighter open concept. This means that in addition to a higher air flow velocity, the 2013 device also produces less resistance of the air stream around the specimen by using perforated adapters. Thus, it is likely that in the 2003 device an air buffer is created around the test specimen which works like an insulation layer, whereas no such air buffer can be stabilized in the 2013 device. Together with the lower air flow velocity, the cooling rate of the specimen temperature is decreased as shown in Figure 5 above. This is the actual cause for deviations in failure temperatures between the 2003 and 2013 device.
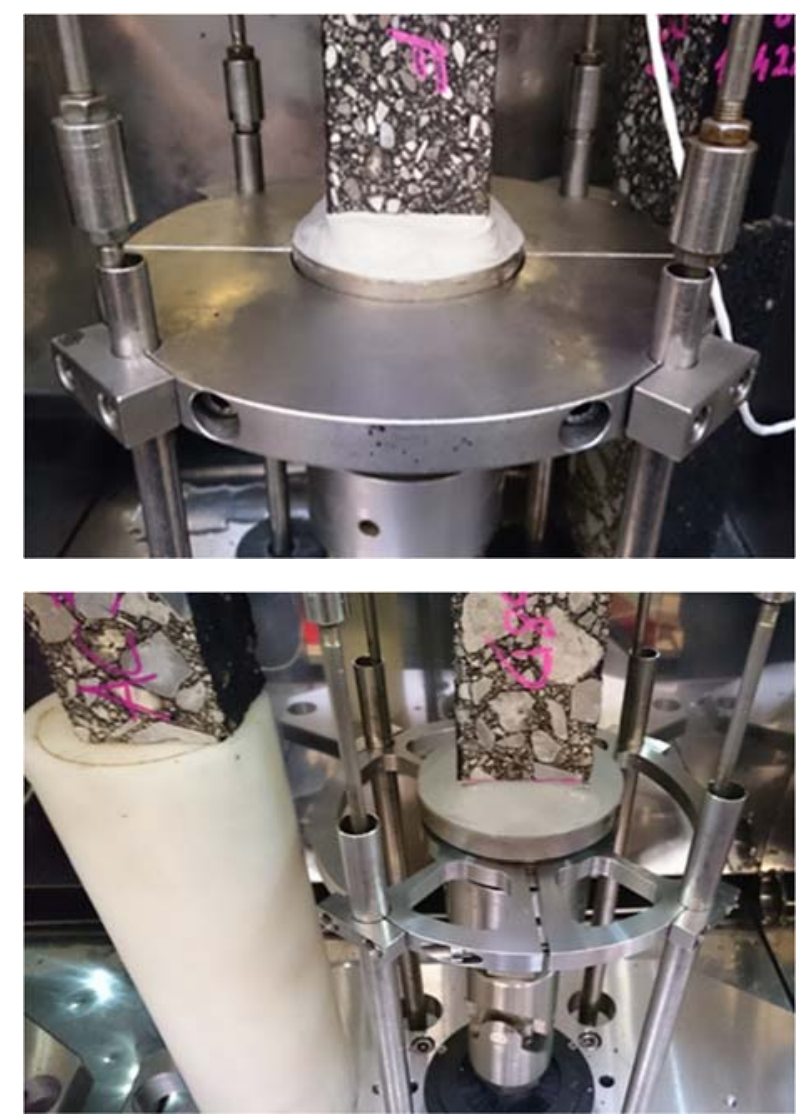

Figure 6. Adapters holding the Invar steel rods in the 2003 (top) and the 2013 device (bottom).

To validate the impact of air flow velocity on lag between air and specimen core temperature, an efficient, quick and simple adaption of the 2003 device was set up. Two fans similar to models that are used for cooling central processing units (CPU) of desktop personal computers (PC) were placed on the bottom of the thermal chamber close to the air outlet. Figure 7 shows the setup. The fans' stream direction was adjusted so that the actual test and the dummy specimen were in the centre of the air stream. 2 different pairs of fan types were used with 3 different settings to study the impact of fan power: a 12 Voltage standard PC fan (air flow velocity max. $2.9 \mathrm{~m} / \mathrm{s}$ ) and a regulable 18-30 Voltage fan (used settings: $20 \mathrm{~V} ; 5.2 \mathrm{~m} / \mathrm{s}$; and $29 \mathrm{~V} ; 7.0 \mathrm{~m} / \mathrm{s}$ ). The thermal program was carried out with one dummy specimen in the 2003 device again, this time including the supporting fans. The air and specimen core temperature was recorded.

The results of the improved setup in the 2003 device are presented in Figure 8 for the AC 22 binder dummy with a cross section of $6 \times 6 \mathrm{~cm}$. The left diagram shows the evolution of the temperature lag between air and core temperature vs. TSRST temperature, the right diagram shows the maximum temperature lag that occurs throughout the thermal program. While the initial setup of the 2003 device leads to a temperature lag of $10^{\circ} \mathrm{C}$, it can be significantly reduced by implementing additional fans and therefore increasing the air flow velocity in the chamber. Even a low powered fan brings down the temperature lag by $4^{\circ} \mathrm{C}$. With the strongest fans, the temperature lag could be 
brought down to same level as for the 2013 device. These results show that the difference in temperature lag between the two devices is strongly related to the air flow velocity within the temperature chamber and that a higher air flow velocity can be easily realized. Looking at the results using the fan with a voltage of $29 \mathrm{~V}$, it can be seen, that the temperature lag is decreasing below $-30^{\circ} \mathrm{C}$. Due to the high power of the additional fans, the cooling system is influenced heavily. Both fans are positioned at the outlet of the system. Therefore, air is suck out of the cooling unit and leads to system errors at low temperatures. After the test program, slight adjustments of the fan positions were made. Placing the fans at higher positions within the chamber in horizontal directions solved those issues. The global air flow of the cooling system is not influenced anymore. Instead of that the local air flow around the specimen is improved.

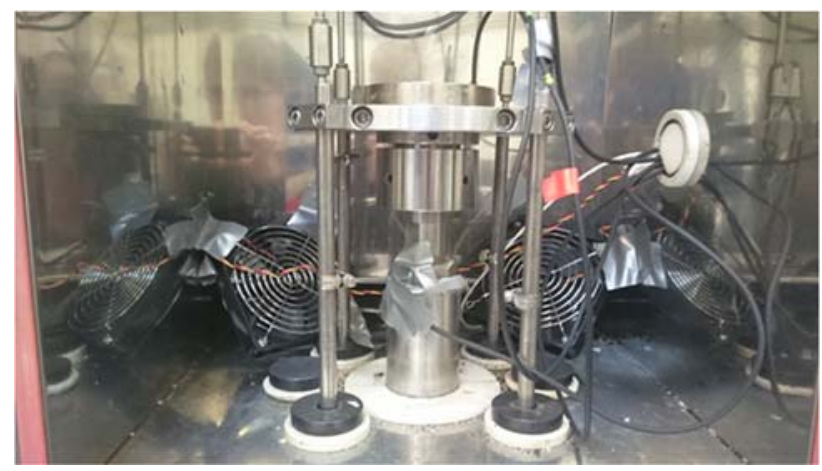

Figure 7. Improvised, improved setup to increase air flow velocity in the $\mathbf{2 0 0 3}$ device.

Specimen Cooling - device 2013 vs. 2003 + improved setup AC 22 binder 6x6cam - temperature lag |air-specimen
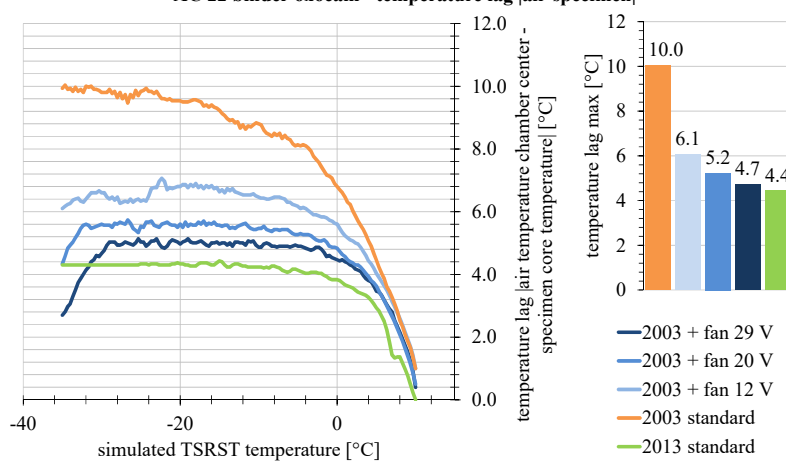

Figure 8. First improved setup to increase air flow velocity in the 2003 device.

\section{Summary and Outlook}

The presented study analyses differences in principle results, i.e. failure temperature, between two test devices for TSRST. Both devices, an older version from 2003 and a newer one from 2013, comply with all requirements given by the US and European Standards in terms of accuracy and resolution of loading and displacement, as well as temperature control. Still, the 2003 device results in $3^{\circ} \mathrm{C}$ lower failure temperatures than the 2013 device. An investigation into the displacement control that ensures that the specimen length is kept constant throughout the test found that both devices manage to hold the specimen length constant. A further investigation into air and specimen core temperature upon cooling revealed that the air temperature rate is comparable and close to the target of $-10^{\circ} \mathrm{C} / \mathrm{h}$ but that the specimen core temperature in the 2003 device is significantly higher than in the 2013 device throughout the test. Thus, the specimen cools down more slowly in the 2003 device which leads to systematically better results in terms of failure temperature. The paper shows that differences in air flow velocities in both devices are responsible for these deviations in specimen core temperature. Low air flow velocities in the 2003 device lead to an air buffer that works like an insulation layer around the specimen. By enhancing the air flow velocities in the 2003 by installing additional fans in the thermal chamber, the specimen core temperature could be lowered and is now comparable to the 2013 device.

This shows that the current testing standards fall short of setting requirements for the thermal chamber accurately enough to ensure reproducible results. Not only air temperature and its cooling rate is of importance, as is the temperature lag between air and specimen core temperature and the air flow within the chamber. A constant air flow around the specimens needs to be ensured.

Next steps in the study will be to run TSRST in the enhanced 2003 device and compare results to the 2013 device. It is expected that the improved air flow velocity will lead to more reproducible results. In addition, a larger round robin study should analyze the presented effects in other devices around the world, overcome differences and produce data for reproducibility of standard TSRST.

\section{References}

[1] NAPA, N.A.P.A. Engineering Overview, accessed 14.02.2017, 2017, www.asphaltpavement.org.

[2] K. Mollenhauer et al., Re-Road - End of life strategies of asphalt pavements | D2.7 Impact of Reclaimed Asphalt characteristics on Mix Design and Performance - Final Report. 2012, European Comission DG Research.

[3] D. Steiner, B. Hofko, M. Dimitrov, R. Blab, Impact of Loading Rate and Temperature on Tensile Strength of Asphalt Mixtures at Low Temperatures, in: A. Chabot et al. (Eds.), 8th RILEM International Conference on Mechanisms of Cracking and Debonding in Pavements, Springer Netherlands: Dordrecht. 2016, 69-74. https://doi.org/10.1007/978-94-024-0867-6 10

[4] C.L. Monismith, G.A. Secor, K.E. Secor, Temperature induced stresses and deformations in asphalt concrete. Journal of the Association of Asphalt Paving Technologists (1965) 34: 248-285.

[5] T.R.J. Fabb, The influence of mix composition, binder properties and cooling rate on asphalt cracking at low-temperature. Journal of the Association of the Asphalt Paving Technologists (1974) 43: 285-331.

[6] W. Arand, Influence of bitumen hardness on the fatigue behavior of asphalt pavements of different thickness due to bearing capacity of subbase, traffic loading, and temperature. Proc 6th Int Conf on Structural Behavior of Asphalt Pavements, 1987, 65-71.

[7] L. Aleshire, et al., Constructability of polymer-modified asphalts in Alaska. Cold Regions Impact on Civil Works (1998): 176-187.

[8] R. Fortier, T. Vinson, Low-temperature cracking and aging performance of modified asphalt concrete specimens. Asphalt Mixtures (1998) 1630: 77-86. https://doi.org/10.3141/1630-10

[9] U. Isacsson, H. Zeng, Low-temperature cracking of polymermodified asphalt. Mater Struct (1998) 31 (205): 58-63. https://doi.org/10.1007/BF02486415 
[10] S.A.M. Hesp, T. Terlouw, W.C. Vonk, Low temperature performance of SBS-modified asphalt mixes. Journal of the Association of Asphalt Paving Technologists (2000) 69: 540-573.

[11] U. Isacsson, H.Y. Zeng, Relationships between bitumen chemistry and low temperature behaviour of asphalt. Constr Build Mater (1997) 11(2): 83-91.

https://doi.org/10.1016/S0950-0618(97)00008-1

[12] G.R. Chehab, Y.R. Kim, Viscoelastoplastic continuum damage model application to thermal cracking of asphalt concrete. J Mater Civ Eng (2005) 17(4): 384-392.

https://doi.org/10.1061/(ASCE)0899-1561(2005)17:4(384)

[13] F. Olard, H. Di Benedetto, The "DBN" model: A thermo-viscoelasto-plastic approach for pavement behavior modeling. Journal of the Association of Asphalt Paving Technologists: From the Proceedings of the Technical Sessions (2005) 74: 791-827.

[14] G.B. Way, K.E. Kaloush, J.B. Sousa, Observations on current performance tests and prediction models for asphalt concrete mixes. Advanced Characterisation of Pavement Soil Engineering Materials, Vols 1 and 2, 2007, 255-269.

[15] N. Tapsoba, H. Baaj, C. Sauzeat, H. Di Benedetto, M. Ech, 3D Analysis and Modelling of Thermal Stress Restrained Specimen Test (TSRST) on Asphalt Mixes with RAP and Roofing Shingles. Constr Build Mater (2016) 120: 393-402.

https://doi.org/10.1016/j.conbuildmat.2016.05.092

[16] L.N. Mohammad, M.M. Hassan, B. Vallabhu, M.S. Kabir, Louisiana's Experience with WMA Technologies: Mechanistic, Environmental, and Economic Analysis. J Mater Civ Eng (2015) 27(6): 04014185.

https://doi.org/10.1061/(ASCE)MT.1943-5533.0001143

[17] E. Nielsen, Comparison between SBS and crumb rubber modified asphalt-laboratory and field study. Asphalt Pavements, Vols 1 and 2, 2014, 893-901. https://doi.org/10.1201/b17219-110

[18] B. Hofko et al., Impact of Field Ageing on Low-Temperature Performance of Binder and Hot Mix Asphalt. In: Proc 12th ISAP Conference on Asphalt Pavements. 2014. Raleigh, NC. https://doi.org/10.1201/b17219-52

[19] CEN, EN 12697-46: Bituminous mixtures - Test methods for hot mix asphalt - Part 46: Low temperature cracking and properties by uniaxial tension tests. 2012.

[20] M. Spiegl, Tieftemperaturverhalten von bituminösen Baustoffen : labortechnische Ansprache und numerische Simulation des Gebrauchsverhaltens. TU Wien, 2007. 